OPEN ACCESS

Edited by:

Ali Derakhshan,

Golestan University,

Iran

Reviewed by:

Liu Wei,

Xinyang Normal University,

China

Liqaa Habeb Al-Obaydi, University of Diyala,

Iraq

${ }^{*}$ Correspondence:

Juan Liu

zzkf2008@163.com

Specialty section:

This article was submitted to

Educational Psychology,

a section of the journal

Frontiers in Psychology

Received: 30 July 2021

Accepted: 09 August 2021

Published: 07 September 2021

Citation:

Liu J (2021) The Role of Grit in Students' L2 Engagement in the

English as a Foreign Language

Classroom.

Front. Psychol. 12:749844. doi: 10.3389/fpsyg.2021.749844

\section{The Role of Grit in Students' L2 Engagement in the English as a Foreign Language Classroom}

\author{
Juan Liu* \\ Department of Foreign Languages, Inner Mongolia University of Finance and Economics, Hohhot, China
}

Due to the rapid development of teaching and learning English as a Foreign Language $(\mathrm{EFL})$, on the one hand, and the arrival of positive psychology (PP) in the process of language education, on the other hand, student engagement has been burgeoned and got a noteworthy role in the academic field. The present review attempts to investigate the relationship of grit with students' L2 engagement, by examining both backgrounds and consequences of grit. Consequently, the effectiveness of findings for policymakers and academic experts is discussed, along with the prominence of strengthening grit in the scholastic contexts in order to cultivate character in learners and improve their prospects.

Keywords: foreign language class, grit, students L2 engagement, policymakers and academic experts, scholastic contexts

\section{INTRODUCTION}

With the enhancement of positive psychology (PP), scholars have regularly discerned its significant role in the second language acquisition (SLA) field (MacIntyre and Mercer, 2014; MacIntyre et al., 2019a). In the psychology and learning domain, PP has represented abundant attention in recent years (Seligman et al., 2006; Karlen et al., 2019; Wang et al., 2021). Seligman and Csikszentmihalyi (2014) acknowledged the objectives of PP and delineated the three aspects in the PP study, namely constructive individual behaviors, progressive involvements, and positive associations. Gabryś-Barker and Gałajda (2016) highlighted that those students' behaviors, encouraging feelings, and learning situations are three significant facets that affect students' presentation in language education.

Positive psychologists have tried to improve the attentiveness of how regular persons flourish under more non-threatening circumstances to catalyze a shift in the emphasis of consciousness from concentration only on replacing the wickedest issues in life to shape constructive eminences (Seligman and Csikszentmihalyi, 2000). One of the desired learners' involvements in the educational performance field is their engagement, which is hypothesized as covering the emotional, cognitive, and behavioral scopes (Mercer, 2019). Behavioral engagement talks about the students' actual disposition to take part in tasks, while emotional engagement is perceived as learners' emotional state of commitment and connection to a task (Mercer, 2019). In addition, cognitive engagement occurs when one is effectively and emotionally faced, and captivated by an individual's work (Lei et al., 2018). However, regardless of its short history, engagement has extended remarkable prevalence in educational investigation entrenched in PP (Mercer and Dörnyei, 2020). 
Mastering a second/foreign language (L2) is a broad practice; therefore, L2 students will during this process, without a doubt, face disappointments, and demoralizations. Nonetheless, L2 students' reactions to these disappointments can be unique. Some may see disappointment as a sign of an absence of insight and fitness and probably will not place more conviction into learning a language (Khajavy et al., 2021). Others may see disappointment as a natural part of language learning and focus more on learning L2; accordingly, L2 students' observations of their L2 learning capacity are identified with their strength in $\mathrm{L} 2$ training.

As declared by Khajavy et al. (2021), the connection among these impressions of L2 learning capacity and exertion in L2 education could be clarified by grit, as a positive, non-intellectual attribute, which has as of late gotten a lot of consideration.

As stated by Keegan (2017), grit has been recommended to assume a critical part in assisting learners with putting forth the ideal attempt to further develop their English language capability despite the difficulties they face. The idea of grit as an indicator and basic component of success and accomplishment has been of significant interest in character and learning psychology throughout previous years. Grit has additionally been receiving attention in further diverse areas, containing business, medical services, and instruction (Sudina et al., 2021). Grit is viewed as an individual quality regular in leaders, and a significant forerunner of progress and greatness in each domain paying little mind to skill or ability (Duckworth and Yeager, 2015).

Additionally, grit is a self-guideline and non-intellectual behavioral characteristic made out of two center aspects: (a) persistence of effort and (b) constancy of interests (Duckworth and Quinn, 2009). The former is the effortful quest for objectives despite mishaps. The latter is responsibility and energy devoted to one objective. A mix of these two characteristics has been anticipated for several years, as grit is planned to catch the long-conversed collaboration between the "energy and persistence" needed to influence enduring objectives (Duckworth, 2016).

Since the effective authority of an L2 is profoundly subject to L2 students' supported exertion and energy throughout an extensive time (Dörnyei and Ushioda, 2013), research of grit and its connection to learners' language accomplishment turns out to be promptly pertinent in SLA. By comprising commitment and accomplishment as results, the discrepancy impacts between grit and accomplishment and grit and commitment can be inspected; thereby, revealing different advantages that grit might bring to learners' education. As learner attentiveness has been demonstrated to be a noteworthy school element for learners' accomplishment and well-being (Wang and Eccles, 2012), commitment will be analyzed as an autonomous scholarly result of grit.

Studies have proved that grit is significantly associated with desire, resilience, well-being, enthusiasm, pleasure, and life fulfillment (Calo et al., 2019; Karlen et al., 2019; Moen and Olsen, 2020; Shakir et al., 2020), while it is negatively interrelated to burnout, hopelessness, and stress (Datu et al., 2019; Moen and Olsen, 2020; Shakir et al., 2020).
For years, grit, as a non-cognitive personality attribute, had a fundamental role in student accomplishment (Duckworth and Quinn, 2009) and spiritual paradigms such as despair and enthusiasm (Steinmayr et al., 2018; Datu et al., 2019). Keegan (2017) emphasized that grit can efficiently stimulate efficacious education in English for Foreign or Second Language Learners (EFL/ESL) who are supposed to dedicate high levels of consideration to English. Although, grit has been examined in other realms, particularly in psychology (e.g., Duckworth et al., 2007, 2009), few studies have regarded it among EFL learners. Undeniably, few inquiries have investigated the rapport between grit and language acquisition, regardless of grit's noticeable part in language learning in comparison to other issues (MacIntyre et al., 2019b). Despite the wide range of research undertaken to date, to the best of the researcher's knowledge, the effect of grit on language engagement is not presupposed.

\section{GRIT}

Grit comprises two lower-order segments, the persistence of exertion and constancy of well-being (Duckworth et al., 2007). The primary sub-construct, persistence of exertion, shows a capacity to keep up with exertion for a long time notwithstanding challenges or disappointment. The second sub-concept, constancy of interests, alludes to the capacity to support comforts for a long period notwithstanding difficulties or misfortunes.

Grit is a moderately new hypothesis created by Duckworth (2016) that associates the constructs of zeal and determination to one's capacity to effectively reach their objectives and Duckworth (2016) asserted that grit clarifies why some are successful in rushing into their objectives, while others are not. Grit is the energy one needs to stay with long-term life objectives regardless of the hardships, disappointments, or difficulties experienced (Duckworth and Gross, 2014; Duckworth, 2016). Grittier people see life as a long-distance race and show a solid hard-working attitude and responsibility. The construct of grit does not propose that people do not encounter disappointments or misfortunes, but that they can remain on track and press forward toward their definitive objective. Grit develops over a long period of figuring out how to manage and move past dismissal and disappointment (Duckworth, 2016). It is created as an individual learns the contrast between low-level objectives and higher-level objectives and figures out where to put their energies. Duckworth (2016) believed that it is not the ability that makes an individual gritty, rather the eagerness to continue learning and developing through one's zeal for a movement. Duckworth (2016, p. 42) expressed, "talent is how quickly your skills improve when you invest effort." When these improved abilities are used, accomplishment develops. The exclusive requirements set upon instructors highlight the pertinence of grit as a significant personality characteristic (Robertson-Kraft and Duckworth, 2014).

Educational psychologists (e.g., Duckworth et al., 2007; Strayhorn, 2014) have presented an intense attentiveness in grit and its inspiration on learners in scholastic situations and findings proved that gritty students commonly outperformed 
in exams than less gritty learners. Grittier learners also display developed educational hopes and show developed degrees of education from schools (Eskreis-Winkler et al., 2014). Although, Ivcevic and Brackett (2014) have not reported any relation between grit and learners' accomplishment, the meta-analysis done by Credé et al. (2017) represented a positive correlation between students' grittiness and their educational presentation.

\section{IMPLICATIONS AND FUTURE DIRECTIONS}

The current minireview tried to focus on the considerate aspect of grit in the EFL setting, particularly about learning engagement. In line with applied perception, it is suggested that EFL students may take advantage of activities or mediations intended to enhance constructive behaviors, such as grit and consistency. Within the EFL setting, some tasks and actions simplifying grit may be prepared to boost learners to set long-term goals constructed on their benefits. To accomplish these objectives, practice is required particularly concerning the mechanisms of failure and obstacles, teaching students how to hold failure as a prospect to be engaged.

The review provides fundamental proof about the significance of considering the settings in which learners are establishing their grit. It is overcritical that instructors, researchers, and authorities change from a reductionist perspective of students' grit, with which the learners are seen as either gritty or not to reflect whether class settings care for all students' grit. This is primarily precise for learners who face wide degrees of difficulties in their normal lives and so may have extreme grit. If grit should be engaged in instructive settings, instructors and policymakers need to discover significant methodologies of evaluating and reinforcing learners' grit. Scholars, specifically, have a pledge to inspect grit regarding learner results as well as in terms of students' more extensive conditions.

A noticeable distinctive of grit is its flexibility (Clark and Malecki, 2019), which means grit can be amended by involvement

\section{REFERENCES}

Calo, M., Peiris, C., Chipchase, L., Blackstock, F., and Judd, B. (2019). Grit, resilience and mindset in health students. Clin. Teach. 16, 317-322. doi: $10.1111 /$ tct. 13056

Clark, K. N., and Malecki, C. K. (2019). Academic Grit Scale: psychometric properties and associations with achievement and life satisfaction. J. Sch. Psychol. 72, 49-66. doi: 10.1016/j.jsp.2018.12.001

Credé, M., Tynan, M. C., and Harms, P. D. (2017). Much ado about grit: a meta-analytic synthesis of the grit literature. J. Pers. Soc. Psychol. 113, 492-511. doi: 10.1037/pspp0000102

Datu, J. A. D., King, R. B., Valdez, J. P. M., and Eala, M. S. M. (2019). Grit is associated with lower depression via meaning in life among Filipino high school students. Youth Soc. 51, 865-876. doi: 10.1177/0044118.X187.60402

Derakhshan, A. (2021). The predictability of Turkman students' academic engagement through Persian language teachers' nonverbal immediacy and credibility. J. of Teach. Persian to Speakers of Other Lang. 10, 3-26. doi: 10.30479/jtpsol.2021.14654.1506

Dörnyei, Z., and Ushioda, E. (2013). Teaching and Researching: Motivation. 2nd Edn. London: Routledge. in the classes. In the SLA setting, the flexibility of grit can arrange for L2 teachers with an instrument to make their learners overcome the probable obstacles they might come upon throughout the L2 procedure. It could accordingly be maintained that regardless of the significant role of grit in learners' educational success, it has not been satisfactorily premeditated, especially in the EFL setting. As a result, mastery of the role of grit deals with new standpoints for higher teaching supervisors when bearing in mind the students' academic presentation. Grit is a disposition attribute that can be fostered and taught to scholars (Ebadi et al., 2018). Higher academic administrators can improve grit in students by providing chances to undertake long-term purposes worthy of learners' determination and providing a demanding and compassionate setting to accomplish their objectives. Instructors and experts could accentuate fulfillment with peer relationships in the development of instruction by encouraging supportive and collaborative peer tasks and actions that enable group cooperative learning to support them in the process of learning, surge their degree of grit and increase their educational presentation, engagement, and determination (Lan and Moscardino, 2019; Derakhshan, 2021; Xie and Derakhshan, 2021).

Grit has got significant consideration as an important personality aspect that needs to be reinforced in youth and has been acknowledged divergent from care in its multifaceted confidence on both attention and strengths (Duckworth et al., 2007). As grit involvements and correlated experimental investigations are still emergent, more studies are compulsory regarding if grit is to some degree teachable in school or not, and if so, focus on the suggested approach to teach it. These are the current issues that must be taken into account by researchers and scholars.

\section{AUTHOR CONTRIBUTIONS}

The author confirms being the sole contributor of this work and has approved it for publication.

Duckworth, A. L. (2016). Grit: The Power of Passion and Perseverance. New York, NY: Scribner.

Duckworth, A., and Gross, J. J. (2014). Self-control and grit: related but separable determinants of success. Curr. Dir. Psychol. Sci. 23, 319-325. doi: $10.1177 / 0963721414541462$

Duckworth, A. L., Peterson, C., Matthews, M. D., and Kelly, D. R. (2007). Grit: perseverance and passion for long-term goals. J. Pers. Soc. Psychol. 92, 1087-1101. doi: 10.1037/0022-3514.92.6.1087

Duckworth, A. L., and Quinn, P. D. (2009). Development and validation of the short grit scale. J. Pers. Assess. 91, 166-174. doi: 10.1080/00223890 802634290

Duckworth, A. L., Quinn, P. D., and Seligman, M. E. (2009). Positive predictors of teacher effectiveness. J. Posit. Psychol. 4, 540-547. doi: 10.1080/ 17439760903157232

Duckworth, A. L., and Yeager, D. S. (2015). Measurement matters: assessing personal qualities other than cognitive ability for educational purposes. Educ. Res. 44, 237-251. doi: 10.3102/0013189X15584327

Ebadi, S., Weisi, H., and Khaksar, Z. (2018). Developing an Iranian ELT contextspecific grit instrument. J. Psycholinguist. Res. 47, 975-997. doi: 10.1007/ s10936-018-9571-x 
Eskreis-Winkler, L., Duckworth, A. L., Shulman, E. P., and Beal, S. (2014). The grit effect: predicting retention in the military, the workplace, school, and marriage. Front. Psychol. 5:36. doi: 10.3389/fpsyg.2014.00036

Gabryś-Barker, D., and Gałajda, D. (2016). Positive Psychology Perspectives on Foreign Language Learning and Teaching. New York: Springer. doi:10.103 7/0003-066x.56.3.218

Ivcevic, Z., and Brackett, M. (2014). Predicting school success: comparing conscientiousness, grit, and emotion regulation ability. J. Res. Pers. 52, 29-36. doi: 10.1016/j.jp. 2014.06.005

Karlen, Y., Suter, F., Hirt, C., and Merki, K. M. (2019). The role of implicit theories in students' grit and mindset in language learning grit, achievement goals, intrinsic and extrinsic motivation, and achievement in the context of a long-term challenging task. Learn. Individ. Differ. 74, 101-757. doi: 10.1016/j.lindif.2019.101757

Keegan, K. (2017). Identifying and building grit in language learners. Eng. Teach. Forum 55, 2-9.

Khajavy, G. H., MacIntyre, P. D., and Hariri, J. (2021). A closer look at grit and language mindset as predictors of foreign language achievement. Stud. Second. Lang. Acquis. 43, 379-402. doi: 10.1017/S0272263120000480

Lan, X., and Moscardino, U. (2019). Direct and interactive effects of perceived teacher-student relationship and grit on student wellbeing among stay-behind early adolescents in urban China. Learn. Individ. Differ. 69, 129-137. doi: 10.1016/j.lindif.2018.12.003

Lei, H., Cui, Y., and Zhou, W. (2018). Relationships between student engagement and academic achievement: a meta-analysis. Soc. Behav. Pers. 46, 517-528. doi: $10.2224 /$ sbp. 7054

MacIntyre, P. D., Gregersen, T., and Mercer, S. (2019a). Setting an agenda for positive psychology in SLA: theory, practice, and research. Mod. Lang. J. 103, 262-274. doi: 10.1111/modl.12544

MacIntyre, P. D., and Mercer, S. (2014). Introducing positive psychology to SLA. Studies in Second Lang. Learn. and Teach. 4, 153-172. doi: 10.14746/ ssllt.2014.4.2.2

MacIntyre, P. D., Ross, J., and Sparling, H. (2019b). Flow experiences and willingness to communicate: connecting Scottish garlic language and traditional music. J. Lang. Soc. Psychol. 38, 536-545. doi: $10.1177 / 0261927 X 19867364$

Mercer, S. (2019). "Language learner engagement: setting the scene," in Second Handbook of English Language Teaching. ed. X. Gao (Basel, Switzerland: Springer), 1-19. doi: 10.1007/978-3-030-02899-2_40

Mercer, S., and Dörnyei, Z. (2020). Engaging Language Learners in Contemporary Classrooms. Cambridge: Cambridge University Press.

Moen, F., and Olsen, M. (2020). Grit: a unique protective factor of coaches' well-being and burnout? New Ideas Psychol. 59, 100-794. doi: 10.1016/j. newideap sych. 2020.100794

Robertson-Kraft, C., and Duckworth, A. L. (2014). True grit: trait-level perseverance and passion for long-term goals predict effectiveness and retention among novice teachers. Teach. Coll. Rec. 116, 1-27.
Seligman, M. E. P., and Csikszentmihalyi, M. (2000). Positive psychology: an introduction. Am. Psychol. 55, 5-14. doi: 10.1037/0003-066X.55.1.5

Seligman, M. E. P., and Csikszentmihalyi, M. (eds.) (2014). "Flow and the foundations of positive psychology" in Positive Psychology: An Introduction. (Dordrecht: Springer), 279-298. doi: 10.1037//0003-066X.55.1.5

Seligman, M. E., Rashid, T., and Parks, A. C. (2006). Positive psychotherapy. Am. Psychol. 61, 774-778. doi: 10.1037/0003-066X.61.8.774

Shakir, H. J., Cappuzzo, J. M., Shallwani, H., Kwasnicki, A., Bullis, C., Wang, J., et al. (2020). Relationship of grit and resilience to burnout among US neurosurgery residents. World Neurosurg. 134, e224-e236. doi: 10.1016/j. newideapsych.2020.100794

Steinmayr, R., Weidinger, A. F., and Wigfield, A. (2018). Does students' grit predict their school achievement above and beyond their personality, motivation, and engagement? Contemp. Educ. Psychol. 53, 106-122. doi: 10.1016/j.cedpsych.2018.02.004

Strayhorn, T. L. (2014). What role does grit play in the academic success of black male collegians at predominantly white institutions? J. Afr. Am. Stud. 18, 1-10. doi: 10.1007/s12111-012-9243-0

Sudina, E., Vernon, T., Foster, H., Del Villano, H., Hernandez, S., Beck, D., et al. (2021). Development and initial validation of the L2 teacher grit scale. TESOL Q. 55, 156-184. doi: 10.1002/tesq.581

Wang, Y. L., Derakhshan, A., and Zhang, L. J. (2021). Researching and Practicing Positive Psychology in Second/Foreign Language Learning and Teaching: The Past, Current Status and Future Directions. Front. Psychol. doi: 10.3389/ fpsyg.2021.731721

Wang, M. T., and Eccles, J. S. (2012). Social support matters: longitudinal effects of social support on three dimensions of school engagement from middle to high school. Child Dev. 83, 877-895. doi: 10.1111/j.1467-8624.2012.01745.x

Xie, F., and Derakhshan, A. (2021). A conceptual review of positive teacher interpersonal communication behaviors in the instructional context. Front. Psychol. 12:2623. doi: 10.3389/fpsyg.2021.708490

Conflict of Interest: The author declares that the research was conducted in the absence of any commercial or financial relationships that could be construed as a potential conflict of interest.

Publisher's Note: All claims expressed in this article are solely those of the authors and do not necessarily represent those of their affiliated organizations, or those of the publisher, the editors and the reviewers. Any product that may be evaluated in this article, or claim that may be made by its manufacturer, is not guaranteed or endorsed by the publisher.

Copyright (c) 2021 Liu. This is an open-access article distributed under the terms of the Creative Commons Attribution License (CC BY). The use, distribution or reproduction in other forums is permitted, provided the original author(s) and the copyright owner(s) are credited and that the original publication in this journal is cited, in accordance with accepted academic practice. No use, distribution or reproduction is permitted which does not comply with these terms. 